\section{PESTICIDE EXPOSURE AND HEALTH PROBLEMS AMONG HORTICULTURAL PESTICIDE APPLICATORS IN ARUSHA, TANZANIA}

EJ Mrema*, S Mwabulambo, AV Ngowi, SH Mamuya. Muhimbili University of Health and Allied Sciences, Dar es Salaam, Tanzania

\subsection{6/oemed-2018-ICOHabstracts. 1363}

Introduction Exposure to pesticides has been reported to cause adverse health effects, and great numbers of people have been affected globally. Annual severe pesticide poisoning cases amount to 3 million worldwide; 25 million symptomatic occupational pesticide poisonings occur each year among agricultural workers in developing countries. Increased health symptoms have been reported as a result of pesticide exposure. In Tanzania there is limited information on health symptoms associated with pesticides exposure among horticultural pesticide applicators.

Methods A cross-sectional study was conducted among 140 pesticide applicators working in horticultural farms in three districts of Arusha region. Data on demograph, types of pesticides used, spray duration, use of personal protection equipment and neurological symptoms were collected by using a structured questionnaire. To determine the intensity of pesticide exposure, acetylcholinesterase assay was done by using the Test-mate Model 400 device with a photometric sensor. Data were analysed by using SPSS version 20.0.

Results The pesticide applicators were men with mean age $29.59 \pm 6.789$ years and mean work duration of 5.76 \pm 3.036 years. Organophosphate pesticides were commonly used by $95 \%$ of the pesticide applicators. Sixty percent of pesticide applicators reported to use personal protection equipment during pesticide application. The neurological symptoms reported were body weakness, perspiration, headache, painful part of the body, poor appetite, depression and irritation. The mean average of acetylcholinesterase was $26.788 \pm 4.0952 \mathrm{u} / \mathrm{g}$ hgb. About $27 \%$ of pesticide applicators had acetylcholinesterase level below the limit value of $24.5 \mathrm{u} / \mathrm{g}$ hgb.

Conclusion The study shows $27.1 \%$ of pesticide applicators had acetylcholinesterase level below the limit value suggesting that exposure to pesticide may result to the neurological symptoms reported. Therefore specific pesticide management interventions are needed to prevent pesticide exposure and reduce the incidence of neurological health symptoms among the pesticide applicators. Acetylcholinesterase monitoring is needed for horticultural farm workers' surveillance.

\section{OCCUPATIONAL HEALTH SURVEILLANCE ACTIVITIES FOR AGRICULTURAL WORKERS AND ANIMAL BREEDERS IN SOUTHWEST OF IRAN}

${ }^{1} \mathrm{R}$ Tabibi, 'S Tarahomi, 'S Tajzadeh, ${ }^{1} \mathrm{~A}$ Valipour, ${ }^{2} \mathrm{M}$ Sokooti. ${ }^{1}$ Abadan University of medical Sciences, Abadan, Iran; ${ }^{2}$ Milan, Italy

\subsection{6/oemed-2018-ICOHabstracts.1364}

Introduction There are about 1.3 billion workers engaged in agricultural sector which is one of the most hazardous jobs in the world. Farmers are mainly at risk of exposure to physical, chemical and biological or hazards in the workplace. This paper is part of a wide project that will be addressed in health surveillance activities for the agricultural workers, and characterising exposure to biological, chemical and physical risks among farmers and animal breeders in the Region of Abadan district, southwest of Iran.

Methods A cross-sectional study was carried out in Abadan district, southwest of Iran. Two groups of farmers and animal breeders were included in the study. Personal data and sociodemographic and clinical information, personal habits and the results of physical and laboratory examination were obtained by the personal data collection forms through health surveillance activities by expert health professionals. Blood samples were collected from all the subjects, lung function was measured using a spirometer. Data were analysed using IBM SPSS statistics 22 software (IBM, Armonk, NY, USA).

Results The study stresses the significant increase of immune parameters in animal breeders in the Abadan district. Workers in rural areas were relatively at higher risk of zoonoses and occupational diseases than in urban areas.

Conclusion Despite underreporting of occupational diseases in agriculture setting, available data clearly show a significant health risk, and therefore the there is a strong need for conducting health surveillance activities at the workplace in southwest of Iran. The implementation of health surveillance programs for agricultural workers relies on the possibility of creating a system able to reach the workers at their workplaces and with the collaboration of employers' associations, will be able to support enterprises in several issues, including risk assessment and management

\section{OCCUPATIONAL EXPOSURE TO ACEPHATE AMONG OIL PALM PLANTATION WORKERS: GLOVE PERMEATION STUDY}

II Ismail*, 'MNF Roslan, 'MIS Saharuddin, ${ }^{2}$ Isa KAM. ${ }^{1}$ Faculty of Applied Sciences, Universiti Teknologi MARA, Shah Alam, Selangor, Malaysia; ${ }^{2}$ Faculty of Health Science, Universiti Teknologi MARA, Puncak Alam, Selangor, Malaysia

\subsection{6/oemed-2018-ICOHabstracts.1365}

Introduction Spills or splash during mixing, loading and application organophosphate insecticide may entail significant dermal exposure to agricultural workers. Although gloves are religiously worn, the level of chemical protection afforded by these gloves is unclear. In this study, the influence of exposure temperature and duration on glove permeation were investigated for acephate, an organophosphate insecticide used for trunk injection on oil palm trees. Potential contamination on the skin of the workers was also investigated.

Methods Nitrile gloves used by oil palm plantation workers during trunk injection were tested at room temperature and elevated temperature $\left(45^{\circ} \mathrm{C}\right)$, using standard permeation cells. Skin wipe samples were collected from the face and hands of the workers to examine whether acephate still contaminated their skin. Chemicals analysis was via HPLC-UV.

Results Higher maximum flux and greater cumulative permeation of acephate were observed over the 4 hour exposure period. Gloves with 5\% simulated abrasion showed reduced performance compared to new gloves. Contamination on the face and hands of the workers were minimal.

Conclusion Limited protection is provided by gloves, even for diluted acephate, especially at $45^{\circ} \mathrm{C}$. The findings indicate the need for more suitable gloves, with frequent change, especially when working in warmer conditions and where abrasion is observed on the gloves. While workers behaviour was good, emphasis on the correct techniques of glove removal may assist in avoiding transfer of contaminants. 


\section{Shiftwork}

\section{NIGHT-SHIFTS, DNA METHYLATION AND TELOMERE LENGTH: PRELIMINARY RESULTS FROM A SURVEY ON A SAMPLE OF ITALIAN NURSES}

${ }^{1} \mathrm{M}$ Carugno* ${ }^{2} \mathrm{E}$ Crespi, ${ }^{1} \mathrm{~V}$ Bollati, 'L Tarantini, ' $\mathrm{L}$ Dioni, ${ }^{3} \mathrm{D}$ Consonni, ${ }^{2} \mathrm{C}$ Maggioni, ${ }^{2,3} \mathrm{G}$ Costa, ${ }^{1,3} \mathrm{AC}$ Pesatori. 'EPIGET Lab, Dept. Clinical Sciences and Community Health, Università degli Studi di Milano, Milan, Italy; ${ }^{2}$ Dept. Clinical Sciences and Community Health, Università degli Studi di Milano, Milan, Italy; ${ }^{3}$ Occupational Medicine Unit, Fondazione IRCCS Ca' Granda - Ospedale Maggiore Policlinico, Milan, Italy

\subsection{6/oemed-2018-ICOHabstracts. 1366}

Introduction IARC defined shift work as probably carcinogenic to humans (Group 2A), after investigations highlighted an increased breast cancer risk in night-shift female workers. The biological mechanisms underlying this association are still unclear. Hence, we evaluated the relationship between nightshift work and molecular alterations potentially related to increased cancer risk, in detail: DNA methylation of the oestrogen receptor gene (ER-Beta) and tumour suppressor genes (BRCA1, p53, p16), global DNA methylation estimated in repeated elements (LINE-1, Alu) and telomere length (TL).

Methods 46 female nurses (age: 35-45 years) who had been working in night-shifts for at least two years (length of service $\geq$ five years) were recruited at the Policlinico Hospital (Milan, Italy) and matched for age, sex and length of service to 51 colleagues not working in night-shifts. Each subject was administered a structured questionnaire and withdrawn a $12 \mathrm{~mL}$ blood sample. Linear regression models adjusted for age, BMI, parity, smoking habit and oral contraceptive use were then applied.

Results Working in night-shifts (yes/no) was associated with BRCA1 hypomethylation ( $\beta$ : $-0.512,95 \%$ CI: -1.039 to 0.015). When considering also former night-shift workers, the number of years in night-shifts (NYNS) was associated with hypomethylation of BRCA1 ( $\beta$ : $-0.084,95 \%$ CI: -0.127 to $-0.042)$, p53 ( $\beta$ : $-0.072,95 \% \mathrm{CI}:-0.133$ to -0.011$)$ and LINE-1 ( $\beta$ : $-0.043,95 \% \mathrm{CI}:-0.083$ to -0.002$)$. After graphically inspecting the NYNS-TL relationship, we stratified our study population by NYNS $<15$ vs $\geq 15$ years. Among nurses with NYNS $\geq 15$ years, NYNS was associated with telomere shortening ( $\beta$ : $-0.065,95 \% \mathrm{CI}:-0.122$ to -0.008 ) and hypermethylation of BRCA1, p53 and LINE-1.

Conclusion Our results show epigenetic alterations that might play a role in cellular ageing, genomic instability and carcinogenesis. We are currently extending our study to other molecular targets involved in the cascade of events that might bring from night-shift exposure to cancer.

\section{LONG WEEKLY WORKING HOURS AND RISK OF ISCHAEMIC HEART DISEASE AND STROKE}

${ }^{1}$ Ann Dyreborg Larsen*, ${ }^{1}$ Harald Hannerz, ${ }^{2}$ Karen Albertsen, ${ }^{3}$ Hermann Burr, ${ }^{4}$ Martin Lindhardt Nielsen, ${ }^{5}$ Jan Hyld Pejtersen, ${ }^{1,6}$ Anne Helene Garde. ${ }^{1}$ National Research Centre for the Working Environment, Copenhagen, Denmark; ${ }^{2}$ Team Working Life, Copenhagen, Denmark; ${ }^{3}$ National Institute of Occupational Safety and Health, Berlin, Germany; ${ }^{4}$ Lægekonsulenten.dk, Ballerup, Denmark; ${ }^{5}$ Danish Centre of Applied Social Science, Copenhagen, Denmark; ${ }^{6}$ Department of Public Health, University of Copenhagen, Denmark

10.1136/oemed-2018-ICOHabstracts. 1367
Introduction Studies have indicated that long working hours is associated with circulatory diseases. The aim of the present studies was to test if long working hours were prospectively associated with ischaemic heart disease (IHD), usage of antihypertensive drugs (AD) and stroke, in a large randomly selected sample from the general workforce of Denmark.

Methods Self-reported data on weekly working hours from the Danish Labour Force Survey (1999-2013) was linked to national registers. Participants were followed until becoming a case, emigration/dead due other causes or end of study period (2014).

Poisson regression was used to analyse incidence rates as a function of weekly working hours. The analyses were controlled for calendar time, time since start of follow-up, age, sex, SES, night and health care work (the latter two for IHD only).

Result Around 145000 persons were included with 3635 cases of IHD, 20648 cases of $\mathrm{AD}$ and 1737 cases of stroke. With 32-40 hours/week serving as reference, the estimated rate ratios for IHD were 0.95 (95\% CI: 0.85-1.06) for 4148 and $1.07(0.94-1.21)$ for $>48$ hours/week. The corresponding rate ratios for $\mathrm{AD}$ were $0.99(0.95-1.04)$ and 1.02 (0.97-1.08).

In the study of stroke 35-40 working hours/week served as reference. The estimated rate ratios for overall stroke were 0.97 (95\% CI: $0.83-1.13)$ for $41-48,1.10(0.86-1.39)$ for 49-54, and 0.89 (0.69-1.16) for $\geq 55$ hours/week. The estimated rate ratios per one category increase in working hours were 0.99 (0.93-1.06) for overall stroke, $0.96(0.88-1.05)$ for ischaemic stroke and $1.15(1.02-1.31)$ for haemorrhagic stroke.

Discussion The analyses cannot confirm long working hours to be associated with IHD, AD or overall stroke. Data suggest however, that long working hours might be associated with increased rates of haemorrhagic stroke.

\section{CLOCKWISE AND COUNTER-CLOCKWISE JOB SHIFT ROTATION DIFFERENTLY IMPACTS ON WORK-LIFE BALANCE}

${ }^{1}$ Maura Minonzio, ${ }^{1}$ Dana Alon Shiffer, ${ }^{2}$ Mattia Bertola, ${ }^{1,3}$ Franca Dipaola, ${ }^{1,3}$ Enrico Brunetta, ${ }^{4}$ Antonio Roberto Zamunér, ${ }^{1,3}$ Raffaello Furlan, ${ }^{1,3} \mathrm{Franca}$ Barbic* . 'Internal Medicine, Humanitas Research Hospital, Rozzano, Italy; ${ }^{2}$ Surgery Department, Borgomanero Hospital, ASL Novara, Italy; ${ }^{3}$ Department of Biomedical Sciences Humanitas University, Rozzano, Italy; ${ }^{4}$ Department of Physical Therapy, Universidade do Sagrado Coração, Bauru, Brazil

\subsection{6/oemed-2018-ICOHabstracts. 1368}

Introduction Rapidly rotating shiftwork schedule, is common in hospital nurses as it provides continuity to the patients' care. It has been suggested that shift rotation in clockwise (CW) direction produces less disruption of circadian rhythms than counterclockwise (CCW) rotation. Little is known about the effects of different direction of shift rotation on work-life balance, particularly in women characterised by additional commitments and responsibilities in the home and outside of work.

Aim To evaluate if $\mathrm{CW}$ and CCW shift rotation differently impacts on family and social relationships in female nurses.

Methods One hundred healthy hospital nurses (F, 20-50 years) were enrolled. Fifty of them worked in CW (Morning, M; Afternoon, A; Night, N; two rest days) and 50 in CCW (A, $\mathrm{M}, \mathrm{M}, \mathrm{N}$, three rest days) shift rotation direction. A daily 